\title{
Reproductive Herd Management in Dairy Cattles: A Review
}

\author{
Devasee Borakhatariya*, and V.K. Karangiya and N.K. Ribadiya \\ Polytechnic in Animal Husbandry, College of Veterinary Science and Animal Husbandry, \\ Junagadh Agricultural University, Junagadh, India \\ *Corresponding author
}

\section{A B S T R A C T}

\begin{tabular}{l}
$\begin{array}{l}\text { K e y w or d s } \\
\text { Reproductive herd } \\
\text { management, } \\
\text { Dairy cattles }\end{array}$ \\
Article Info \\
\hline $\begin{array}{l}\text { Accepted: } \\
\text { 10 July } 2018 \\
\text { Available Online: } \\
\text { 10 August } 2018\end{array}$ \\
\hline
\end{tabular}

Froman economic point of view, in order to avail better economic growth of a dairy farmwhere modern dairy production systemsis being practised round the year reproductive management is prerequisitein a dairy herd. Reproductive management is a multifactorial taskwhich have direct impact on reproductive performance of dairy cows. In present publication different strategies have been depicted to facilitate improved performance, health and fertility in a dairy farms.

\section{Introduction}

Getting dairy cattle rebred in a timely fashion is critical for dairy farm profitability. With the intensive selection of dairy cows for higher and higher milk production, there is clear evidence from many parts of the world that fertility is in decline. Final goal of the reproduction in a dairy farm is to obtain a calf per year to obtain a pregnancy rate of $90 \%$, thus a 365-day calving index. A special attention was paid to postpartum period and to oestrus detection at the farm level.

In dairy cattle, reproductive inefficiency causes great economical loss to the dairy farmers. Even under optimal conditions, the reproductive process is less than perfect because of the multiple factors involved in producing a live calf (Roberts, 2001). Additionally, reproductive managerial aspects not include only animals but also involve the human resource which is engaged with the feeding, house management, milking and inseminators also.

Extension in the inter-calving period from 12 to 14 months or more on an average result into a substantial reduction in the annual financial return over feeding costs (Berka et al., 2004). 
This extension result into loss of milk as well as calves produced per cow. Economically, there will be considerable financial loss to the farmers for each day's extension of the calving interval beyond 365 days in cows and 395 days in buffaloes. Thus, infertility is one of the important economic losses in high producing animals and modern feeding and management practices on large scale aggravate the problem

Maximal reproductive efficiency requires management of the calving interval. This consists of three major components: Postpartum period (elective waiting period), the breeding period, and gestation (including the dry period) plus.

\section{Post-partum period or elective waiting period}

The first component of a calving interval is the traditional rest period or the elective waiting period (EWP). This period varies from 40 to 70 days on most farms. Part of its duration is based on the physiological need for the reproductive tract of the cow to undergo a healing process or involution. Generally when cows calve without complication, this healing process requires no more than 40 days.

\section{Peri-parturient period}

Parturition in the cow is a process that requires attention, care, and cleanliness. A multitude of calving-related disorders predispose cows to ill health, loss in milk production, and reduced reproductive efficiency. Whatever can be done to reduce one or more of these disorders will result in the reduced incidences of other disorders because of their strong interrelationships. Once parturition occurs, the mammary gland becomes the major nutrient user. As a result, an energy prioritization is manifested that places higher priorities on the use of nutrients for maintenance and for milk secretion than for the onset of estrous cycles and the initiation of a new pregnancy. Cows that consume less DM than their contemporaries have delayed first ovulation and first estrus after parturition, produce less milk, and are less fertile (Butler and Smith, 1989).

\section{Calving pattern}

When calving takes place over a short period of time, it is relatively easy to sustain that pattern of calving. Where it takes place over an extended period of time, it is quite difficult to restore it to a compact pattern. The reasons for this difficulty are several, for an extended calving pattern not only affects the time at which cows can be expected to rebreed successfully, but also affects the patterns of reproductive performance and production in replacement heifers.

The calving pattern affects the age at which heifers are first bred. It is usual to breed all of the replacement heifers simultaneously, so that they all calve at the time when the main herd starts to calve. If they are born from a compact calving pattern, they will all be of a similar age when they are bred. If, however, they come from an extended calving pattern, they will either be at mixed ages when first bred, or the younger ones will have to be bred asynchronously. Hence, in the former situation, some heifers will calve at a relatively younger age than their peers, probably also at a lighter body weight, so will be relatively disadvantaged in competing for food. In the latter situation, the heifer will have a shorter interval between her first parturition and the start of the breeding season and, hence, a reduced probability of conceiving. It is advisable to go through the use of control breeding technique to optimise the calving pattern in farm (Arbel et al., 2001).

For the better reproductive efficiency following criteria should be managed at farm 
level,

A compact calving period is of 2 months. This ensures that calves are of similar age and weight at weaning, improves their overall health and reduces calf mortality by ensuring that late-born calves do not acquire infection from older, earlier-born animals. In addition, cows are at a similar stage in their production cycle; thus their feeding and other aspects of management will be the same.

Cows should calve at the best time of year to utilise the available feed, thus in spring, winter and autumn but not summer.

It is important to use fertile bulls, running with reasonable numbers of cows and heifers. Particularly in heifers, a sire that produces easy calving should be used.

Ideally, heifers should be served so that they calve 2-3 weeks before the cows in the herd, to provide the opportunity for a longer calving-conception interval.

Primipara may lose excessive weight; hence they should be fed separately from and additionally to the rest of the herd. It may be necessary to wean their calves slightly earlier.

\section{Management of the newly born calves}

It is no wonder that newly calved or close-up fresh cows have been the focus of new veterinary intervention. It is logical to assume, however, that whatever stimulates Dry matter intake (DMI) and prevents ill health for closeup fresh cows by providing more available nutrients for reproductive processes will prove beneficial to the cow once maintenance, growth, and milk production requirements are satisfied.

\section{Onset of estrous cycles}

Follicular waves begin soon after calving, concentrations of blood FSH are sufficient, but a major limiting factor to ovulation is the reinitiation of adequate $\mathrm{LH}$ secretion in the form of LH pulses to support final follicular maturation and subsequent ovulation of a dominant follicle. Moreover, the onset of these LH secretory patterns is related to the timing of the postpartum need of energy balance. The stimulation of appetite to ensure adequate DMI in normal, healthy cows is essential to provide nutrients for maximizing milk secretion, follicular growth, ovulation, uterine involution, and the initiation of pregnancy.

Increased feeding frequency and better feed management to maintain a fresh, adequate supply of feed and multiple sources of clean are critical for stimulating appetite and maximal DMI. However, loss of BCS between parturition and AI may negatively influence conception, because cows with BCS $<3$ at calving were less likely to be inseminated and loss of BCS between calving was associated with more days open and delayed intervals to first service. Milk production and DMI of dairy cows are stimulated by increased dietary protein, but, unfortunately, decreased fertility often is associated with excess feeding of ruminally degradable protein. Concentrations of milk urea $\mathrm{N}$ exceeding $19 \mathrm{mg} / \mathrm{dl}$ are associated with altered uterine $\mathrm{pH}$ and reduced fertility. Therefore more research is needed to determine if various diets and changes in nutritional management can be made to improve fertility rather than merely avoiding reductions in fertility.

\section{Inter-service Intervals}

It is the number of days between services - the time from one AI event to the next. While the interval can be measured on an individual-cow basis, it is most useful to look at an average for the entire herd. One of the keys to getting cows and heifers bred efficiently is minimizing the time between their first insemination and subsequent ones, if needed. 
The "inter-service" interval also is sometimes called the "interbreeding interval" or "reinsemination interval." It is common for herds to have inter-service intervals of more than 40 days. But achieving a tighter interval will help to increase a herd's pregnancy rate, decrease average days open and shorten calving intervals. To shorten your inter-service interval, heat detection three weeks after insemination is useful, even in a herd relying primarily on timed AI. Heat detection can be improved by focusing on employee training, maintaining good animal identification (including easy-to-read ear tags) and keeping accurate records. There are now handy cellphone apps that can make it easy for employees to record observed heats. Overall, inter-service intervals can be shortened by improving heat-detection strategies, focusing on strategic and timely pregnancy/open-cow diagnosis and expedient resynchronization of animals that otherwise would go too long before reinsemination.

\section{Target for the Reproductive Herd Management in a Dairy Farm}

\begin{tabular}{|l|l|}
\hline \multicolumn{1}{|c|}{ Parameters } & \multicolumn{1}{|c}{ Herd average } \\
\hline Age at first breeding & $14-15$ months \\
\hline Age at first calving & $22-24$ months \\
\hline Days to first service & 75 days \\
\hline 21-day Pregnancy rate & $>20 \%$ \\
\hline Days open & $115-125$ days \\
\hline Calving interval & 13 months \\
\hline First service conception rate & $40 \%$ or greater \\
\hline Services per conception & less than 2.5 \\
\hline Percent heats observed (efficiency) & $>65 \%$ \\
\hline Inter-estrous interval & $<35$ days \\
\hline
\end{tabular}

\section{Rebreeding breeding}

Programmed breeding is a method to schedule and control the insemination program of lactating cows in the herd. Potential Benefits of the control breeding technique are as follow 1). Improve efficiency of heat detection 2). Control timing of first service postpartum 3). Reduce variation of calving intervals 4). Reduce reproductive culling 5). Improve reproductive performance.

\section{Breeding period/ period of the standing heat}

The duration of this period is a function of the estrus detection rate and the level of individual cow fertility.

The percentage of cows detected in estrus depends on the efficiency of detecting estrus in all cows, while the level of cow fertility depends upon a number of factors, including the fertility of the service sire, correct thawing 
and handling of semen, AI-breeding technique, and timing of insemination.

\section{Detection of estrus}

The greatest limiting factor to successful fertilization is detection of estrus. Approximately $50 \%$ of the estrous periods go undetected on the average dairy farm. Two important challenges exist for detecting estrus: accurately recognizing signs of estrus and identifying all possible periods of estrus in breeding heifers and cows (Rao et al., 2013)

\section{Signs of estrus}

A cow will not be detected to stand if no other cow is available to mount. Once four or more sexually active animals are in estrus in the same pen, standing and mounting activity normally will be maximized.

\section{Estrus-detection aids}

Ideal estrus detection system has the following characteristics: 1) continuous surveillance of the cow; 2) accurate and automatic identification of the cow in estrus; 3 ) operation for the productive lifetime of the cow; 4) minimal labor requirements; and 5) high accuracy and efficiency (95\%) for identifying the appropriate physiological events that correlate with estrus, ovulation, or both.

\section{Gestational and dry period}

The third component of a calving interval is gestation, including the dry period. The duration of gestation is fairly constant and cannot be shortened significantly without adversely affecting the health or viability of the newborn. Dry period is a critical component to subsequent performance of dairy cows. Nutrients required during this period include the maintenance and growth of the cow plus that required by the developing feto-placental unit.

\section{Preventive veterinary practices at farm}

Appropriate preventive herd health programs should include a vaccination program for cows and replacements, deworming of animals on pasture, mastitis control, hoof care, reproductive visits, and other diagnostic procedures applied to blood and tissue samples resulting from abortions and other unexplained illnesses.

\section{Stall level management of animals}

For maximum comfort and milk yield in dairy cows, they must stand to eat, stand to be milked, and lie down to ruminate and rest. Therefore, tie-stall or free-stall comfort is critical to increased milk yields and acceptable conception rates. During times of heat stress, some environmental modification is essential during late gestation and during lactation to prevent hyperthermia and its harmful effects on cows. During the active AI-breeding period, heat stress reduces uterine blood flow oocyte quality, embryo development, luteal function, and endometrial function; and milk yields and overall reproductive performance. Modifications in free-stall or loose housing should include shade, cooling under shades, forced ventilation with fans, and sprinklers (Noordhuizen and Bonnefoy, 2015)

\section{Proper timing of insemination}

Once the egg has ovulated, its estimated viable life is less than $12 \mathrm{hrs}$, unless it becomes fertilized. Sperm are not capable of fertilizing the egg immediately upon thawing and deposition into the uterine body of the female because they must travel the uterine horns to the utero-tubal junction, enter the 
oviduct, and complete a maturation process known as capacitation. In general, normal, motile sperm need about 6 to $10 \mathrm{~h}$ to reach the lower portion of the oviduct (Abubaker et al., 2013). The key to proper timing of insemination and maximizing fertilization rates is to inseminate cows at a time to allow ovulation to occur when adequate numbers of motile sperm are present in the oviduct.

\section{Handling of frozen semen and ai techniques}

The improper handling of semen results in damaged sperm membranes, cold and heatshocked sperm, or impaired sperm motility. To maintain maximum fertilization rates, recommended semen handling techniques must be followed: 1) when removing straws for thawing, prevent exposure of other straws by keeping them below the frost line of the tank; 2) thaw straws in water at $37^{\circ} \mathrm{C}\left(95^{\circ} \mathrm{F}\right)$ for at least $30 \mathrm{sec}$. 3) once thawed, prevent cold shock of sperm cells until the semen is deposited in the female (DuPonte, 2007).

\section{Embryonic losses}

Once the eggs are fertilized, the next obstacle is loss of the early embryo that occurs during the cleavage stage of pregnancy. This is a critical period of development when early losses can occur. The next critical stage is around d 15 or 16 , when the embryo must be developed sufficiently to override the spontaneous uterine secretion of $\mathrm{PGF}_{2} \alpha$. Additional embryonic losses can occur during the period of 25 to $40 \mathrm{~d}$ after insemination. These so-called late embryonic deaths probably occur partly as a result of some failure in the attachment of the developing placenta to the uterine wall (Vassilev et al., 2005). Because of these embryonic and fetal losses, pregnancy diagnosis should be done at least twice. The first should as early as possible to identify non pregnant cows and the second sometime after $\mathrm{d} 70$, because only $3.4 \%$ of pregnancies in lactating dairy cows are lost after $\mathrm{d} 70$.

\section{Fertility and season}

In dairy cows inseminated during the hot months of the year, there is a decrease in fertility. Different factors contribute to this situation; the most important are a consequence of increased temperature and humidity that result in a decreased expression of overt estrus and a reduction in appetite and dry matter intake. Heat stress reduces the degree of dominance of the selected follicle and this can be seen as reduced steriodogenic capacity of its theca and granulosa cells and a fall in blood estradiol concentrations. Plasma progesterone levels can be increased or decreased depending on whether the heat stress is acute or chronic, and on the metabolic state of the animal. These endocrine changes reduce follicular activity and alter the ovulatory mechanism, leading to a decrease in oocyte and embryo quality. The uterine environment is also modified, reducing the likelihood of embryo implantation (De Rensis and Scaramuzzi). Appetite and dry matter intake are both reduced by heat stress thus prolonging the postpartum period of negative energy balance and increasing the calving-conception interval, particularly in high producing dairy cows. The utilization of cooling systems may have a beneficial effect on fertility but dairy cows cooled in this way are still unable to match the fertility achieved in winter.

To improve the farm fertility aforesaid and discussed criteria should be followed.

\section{References}

Abubaker Shameem, P.S., Kurien, M.O., Aravinda Ghosh, K.N., Shibu Simon, Anil, K.S. and Bibin B.B. 2013. 
Ovulation synchronisation for improving fertility in postpartum dairy cows. J. Vet. Anim. Sci., 44: 42-45.

Arbel, R., Bigun, Y., Ezra, E., Sturman, H. and Hojman, D. 2001. The effect of extended calving intervals in high lactating cows on milk production and profitability. J. Dairy Sci., 84: 600-608.

Berka, T., Stipkova, M., Volek, J., Rehak, D., Mateju, G. and Jilek F. 2004. Monitoring of physical activity for management of cow reproduction. Czech Journal of Anim. Sci., 49: 281288.

Butler, W.R. and Smith, R.D. 1989. Interrelationships between energy balance and post-partum reproductive function in dairy cattle. Journal of Dairy Science, 72: 767-783.

De Rensis, F. and Scaramuzzi, R.J. 2003. Heat stress and seasonal effects on reproduction in the dairy cow - a review. Theriogenology, 60: 1139-1151.

DuPonte, M.W. 2007. Proper Semen Handling During an Artificial Insemination Program. Livestock Management, LM-16.

Noordhuizen, J. and Bonnefoy, J.M. 2015. Heat Stress in Dairy Cattle: Major Effects and Practical Management Measures for Prevention and Control. SOJ Vet. Sci., 1(1): 103.

Rao, T. K. S., Kumar, N., Kumar, P., Chaurasia, S. and Patel, N.B. 2013). Heat detection techniques in cattle and buffalo. Vet. World, 6(6): 363-369

Roberts, S.J. 2001. Veterinary Obstetrics and Genital diseases, $2^{\text {nd }}$ Ed., CBS Publisher and Distributors, New Delhi.

Vassilev, N., Yotov, S. and Dimitrov, F. 2005. Incidence of early embryonic death in dairy cows. Trakia J. of Sci., 3(5): 62-64.

\section{How to cite this article:}

Devasee Borakhatariya, and V.K. Karangiya and Ribadiya, N.K. 2018. Reproductive Herd Management in Dairy Cattles: A Review. Int.J.Curr.Microbiol.App.Sci. 7(08): 1332-1338. doi: https://doi.org/10.20546/ijcmas.2018.708.151 